\title{
LA CIUDAD DE SANTIAGO RESIGNIFICADA COMO CORPOREIDAD COMUNICACIONAL TEMPORAL EN TIEMPOS DE ESTALLIDO SOCIAL
}

\author{
A cidade de Santiago resignificada como corpo de \\ comunicação temporário em tempos de despertar social
}

The city of Santiago redefined as a temporary

communication body in times of social unrest

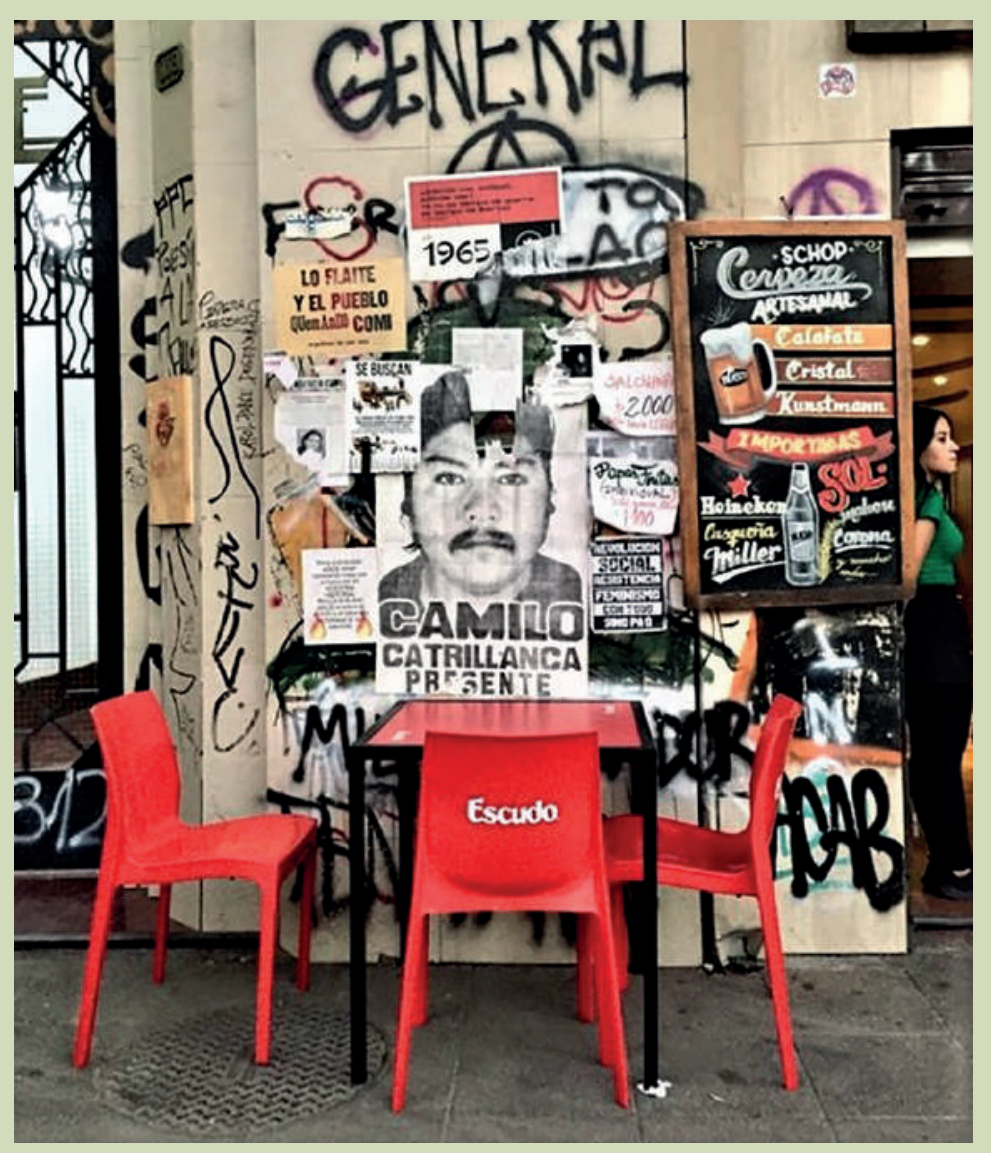

Gabriela Manzi Zamudio

Coordinadora Diplomado en Diseño y Producción de Arquitecturas Temporales, Docente Facultad de Arquitectura y Urbanismo, Universidad de Chile. Docente Diego Portales. Santiago. Chile. gmanzi@uchilefau.cl

https://orcid.org/0000-0001-6153-2922
La Colación.

Fotografía Fernando

Dowling .

https : / /www.

instagram.com $/ \mathrm{p} /$

B6eNXBgJ9dJ/, 2020. 


\title{
RESUMEN
}

El Estallido Social Chileno de octubre de 2019, a través de sus múltiples manifestaciones, ha dado lugar a trasformaciones en la ciudad, por cuanto su arquitectura ha sido utilizada como lienzos comunicacionales, donde tanto las instalaciones temporales espontaneas, así como las diseñadas, han permitido tener nuevas lecturas urbanas. Esta modalidad comunicacional, pone en evidencia una sociedad porosa, activa, dinámica, donde los anhelos y esperanzas requieren ser atendidos y escuchados. Así, el cuerpo urbano se tatúa, expresando las necesidades de una sociedad invisibilizada y desatendida: la arquitectura, se viste para la ocasión, perdiendo su significado inicial y convirtiéndose en un medio de comunicación ciudadano, sin censura.

Desde el frente comunicacional de las instalaciones, revisaremos tres modalidades temporales que intervienen la ciudad, resignificándola: El tatuaje urbano como tipología inherente al Estallido Social proveniente del arte callejero; las Performances y el cuerpo humano como herramienta comunicacional dispuesta simbólicamente en el espacio público y por ultimo las Instalaciones urbanas como la resignificación de un edificio o espacio público a la luz de una intervención que trasgrede su significado original.

El espíritu del cambio, de renovación se toman la ciudad: el cuerpo urbano entra en la vorágine de la permanente transformación, conforme a un ritmo dinámico y espontaneo impreso por la voluntad ciudadana.

Palabras Clave: cuerpo urbano, ciudad, crisis, comunicación, ciudadanía.

\section{RESUMO}

O surto social chileno de outubro de 2019, através de suas múltiplas manifestações, levou a transformações na cidade, uma vez que sua arquitetura foi usada como instrumentos de comunicação, onde tanto as instalações temporárias espontâneas quanto as projetadas permitiram ter novas leituras urbanas. Essa modalidade de comunicação mostra uma sociedade porosa, ativa e dinâmica, onde anseios e esperanças precisam ser abordados e ouvidos. Assim, o corpo urbano é tatuado, expressando as necessidades de uma sociedade invisível e desassistida: arquitetura, veste-se para a ocasião, perde seu significado inicial e se torna um meio de comunicação do cidadão, sem censura.

Nas estruturas de comunicação das instalações, revisaremos três modalidades temporárias que intervêm na cidade, ressignificando-a: a tatuagem urbana como uma tipologia inerente ao despertar social proveniente da arte de rua; as performances e o corpo humano como uma ferramenta de comunicação organizada simbolicamente no espaço público e, finalmente, as instalações urbanas como a ressignificação de um edifício ou espaço público à luz de uma intervenção que transgride seu significado original.

O espírito de mudança e de renovação toma a cidade: o corpo urbano entra no turbilhão da transformação permanente, de acordo com um ritmo dinâmico e espontâneo impresso pela vontade do cidadão.

Palavras Chave: Corpo urbano, cidade, crise, comunicação, cidadania

\begin{abstract}
The Chilean Social Uprising of October 2019, through its multiple manifestations, has led to transformations in the city, as its architecture has been used as communicational canvases where both the spontaneous temporary facilities, as well as those designed, have allowed having new urban readings. This communication modality shows a porous, active, dynamic society, where longings and hopes need to be addressed and heard. Thus, the urban body is tattooed, expressing the needs of an invisible and unheeded society: architecture, is dressed for the occasion, losing its initial meaning and becoming a means of uncensored citizen communication.

From the communicational side of the facilities, we will review three temporary modalities that intervene in the city, redefining it: The urban tattoo as a typology inherent to the Social Uprising coming from street art; the Performances and the human body as a communication tool symbolically arranged in the public space and, finally, the Urban Facilities as the redefinition of a building or public space in the light of an intervention that breaks its original mold.

The spirit of change, of renewal, has taken over the city: the urban body enters the maelstrom of permanent transformation, following the dynamic and spontaneous rhythm printed by the citizen's will.
\end{abstract}

Keywords: urban body, city, crisis, comunication, citizenship 


\section{INTRODUCCIÓN}

\section{CUERPO Y TATUAJE}

En la antigua Grecia tuvo lugar el nacimiento simultáneo e indisoluble de la Ciudad y la Política, al extremo de que no se diferenció la Ciudad del Estado. Esto era posible porque la polis griega, fundada en la democracia, integraba al ciudadano a su actividad, quien la asumía como propia. De esta manera la historia nos enseñó que la ciudad fue la primera forma de participación ciudadana y cómo se construyó la trilogía inseparable compuesta por la Ciudad, el Estado y la Ciudadanía. (Carrión, 1996, p. 2)

El Centro de la Ciudad de Santiago, personificada por el sector de la Plaza de la Dignidad, ha sido resignificado durante el Estallido Social desde dos vertientes que guardan sentido con los orígenes fundacionales de la urbe. Existe, por un lado, una recuperación del rol del ciudadano, como ente activo, reflexivo y opinante de la Ciudad-Estado. Desde este flanco se torna posible visualizar que, desde la participación ciudadana, existe una posibilidad de volver a reconstituir el tejido de un estado que vuelva a velar por los derechos de sus ciudadanos. Por otro, la ciudad requiere demostrar que aquellos cambios son reflejados por su nuevo semblante, revistiéndose de ellos, de manera de evidenciar su íntima complicidad. Para ello, y como fenómeno comunicacional temporal, sus construcciones, espacios públicos, monumentos y esculturas serán sobrescritas por capas de revestimientos ciudadanos, que grabarán sobre sus superficies, las variadas demandas y denuncias ciudadanas.

Ciudadanía y ciudad se encuentran en una relación de profundo compromiso. El Estado es el que no comparece en esta trilogía supuestamente inseparable.

El presente artículo estudiará los niveles comunicacionales que le serán impresos a esta nueva ciudad temporal, los cuales originan escalas de intervenciones, las que tienen al cuerpo, humano y arquitectónico, como foco central de análisis.

Pese a que el Estallido Social aún se encuentra en curso, originando día a día nuevas manifestaciones, tendremos reflexiones referidas a las corporeidades comunicacionales visualizándolas como fenómenos urbano temporales.

El cuerpo del hombre es siempre la mitad posible de un atlas universal (Foucault, 1979, p. 31).

El cuerpo ha sido un tema fundamental del arte, pero también ha sido un lugar central y una metáfora en la que comprender y explorar el cambio social y político (Walzer, 20I5). El cuerpo es una construcción: en el caso del cuerpo humano es una construcción social entendida desde su contexto; en el caso de la arquitectura, en su acepción clásica, es una relación íntima de una obra con el cuerpo humano. En ambas categorías el cuerpo es entendido en una relación con un otro, en una necesidad corpórea, de entendimiento con un otro. 

forma definida. Diversos modelos teóricos señalan que no tiene historia o historicidad, bastándole sólo la espacialidad. [...] La corporalidad, en tanto, hace referencia más bien a la realidad subjetiva, vivenciada o experienciada; por ello está en la intencionalidad de la vida psíquica. La corporalidad es historia vital interna, madura hacia la diferenciación [...]. (Medina, Ornstein, Tapia, 2006, p. 165)

Vestir un cuerpo es adecuarlo para una situación determinada. Cuando los cuerpos se decoran, se ajustan a un lugar para una actividad específica, significando un atributo ético: vale decir, se prepara para comunicar una inflexión, un momento de cambio y también una instancia de renovación. Una arquitectura decorada posee corporeidad, expresión, sentimiento por cuanto se engalana. Al manifestarse, se constituye en un acto comunicacional.

Un revestimiento es un referente a nuestra propia corporeidad, pues nos vestimos de acuerdo a la ocasión. El vestido, o revestimiento, permite que el cuerpo posea significado, lo hace comprensible, aunque lo recubre. El vestido es efímero, pues en el diálogo entre corporeidad y revestimiento nos permite entenderlo.

El tatuaje entendido como revestimiento corporal proviene de una estrategia comunicacional, la cual requiere transmitir que no existe el cuerpo desnudo, que el cuerpo decorado es un cuerpo iniciado en el orden simbólico (Thévoz, 1984, p. I I 8). Un cuerpo dibujado es requerimiento para ser reconocido como especie humana.

Los tatuajes contemporáneos, contradiciendo su origen tribal, son una expresión individual que comunican distintas experiencias de vida, mediante una sumatoria de tatuajes que van midiendo secuencias temporales. Formalmente, se sobreescriben unos sobre otros, poniendo énfasis en una sumatoria de experiencias simultáneas que va midiendo los tiempos.

Las ciudades de Chile, durante el Estallido Social, han sido sobreescritas por un revestimiento ciudadano gráfico, el cual ha dejado grabada sobre sus superficies, en el espíritu del tatuaje contemporáneo, las demandas ciudadanas [Figura I]. El arte urbano, como expresión individual, formará parte de esta vestimenta, aunque de una manera diferente: las sumatorias de técnicas impresas sobre las superficies expresarán un sentir ciudadano, colectivo, tribal, en la lógica del tatuaje contemporáneo, pero también recogiendo su expresión originaria, ancestral, aquel sentido de pertenencia y arraigo a una tribu.

El tatuaje, con su carga comunicacional, convertirá al cuerpo urbano en corporeidad ya que la llevará a expresarse desde las emociones, los pensamientos y sentimientos, convirtiendo a la urbe en una entidad vida. Aquella interacción conformará el nuevo revestimiento urbano del imaginario de las ciudades en crisis. 


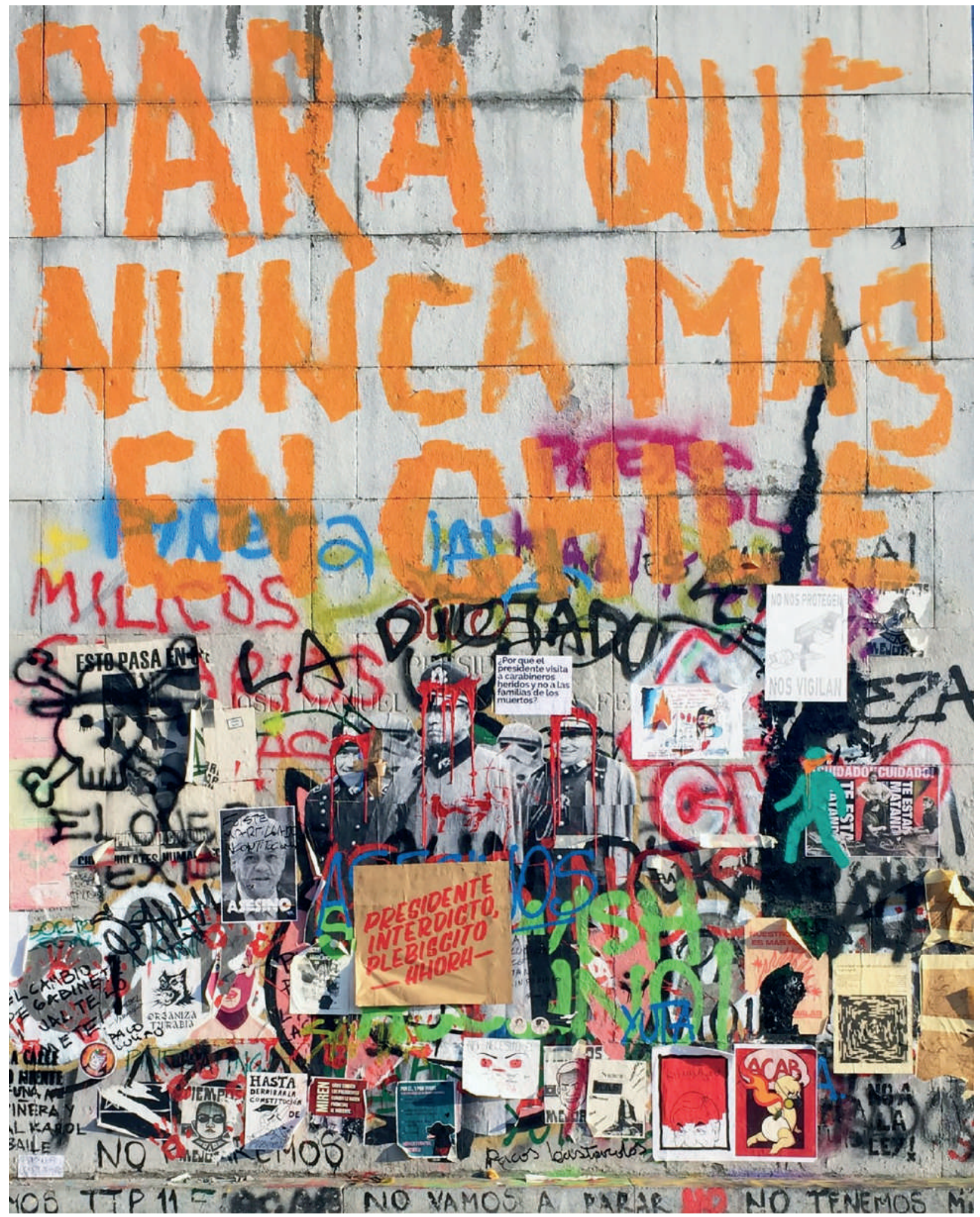




\section{SOPORTES Y CONTEXTO URBANO}

\section{ESTUDIO DE CASOS}

AS / Vol. 38. No57 / ENERO 2020 // ISSN impresa 07 I 6-2677 / ISSN digital 0719-6466

LA CIUDAD DE SANTIAGO RESIGNIFICADA COMO CORPOREIDAD COMUNICACIONAL

TEMPORAL EN TIEMPOS DE ESTALLIDO SOCIAL

Gabriela Manzi Zamudio 
TATUAJES URBANOS, Ciudad y Comunicación confidencial
El paisaje humano de las movilizaciones logra cambiar la escala de la ciudad cuando da origen a las movilizaciones mientras que el paisaje urbano cotidiano [Figura 2], sin marchas, muestra un semblante alterado, acromático, donde la noción de zócalo, aquella pieza clásica arquitectónica donde el edificio toca el suelo relacionándose con las personas, conforma una banda continua, un soporte fijo horadado con expresiones escritas a pulso, estableciendo una nueva, inédita y efímera forma de comunicación ciudadana.

Cada marcha deja nueva información escrita sobre esta corporeidad urbana previamente grabada [Figura 3]. Si los cuerpos tatuados registran sus experiencias de vida, los cuerpos urbanos se entenderán desde esta misma lógica corpórea: vale decir que los tatuajes se sucederán unos sobre otros, dibujados en unas arquitecturas que aceptaran la cultura de lo maquillado, de lo cosmético Esta cosmética comunica el nuevo orden conforme a una inaugurada cosmovisión contemporánea.

El tatuaje urbano viene a realizar una resignificación corpórea, que le recuerda al tatuado su razón de ser, le comunica a los demás su

Figura 2 .

Turistas en el GAM,

Edificio GAM.

Fotografía Fernando

Dowling

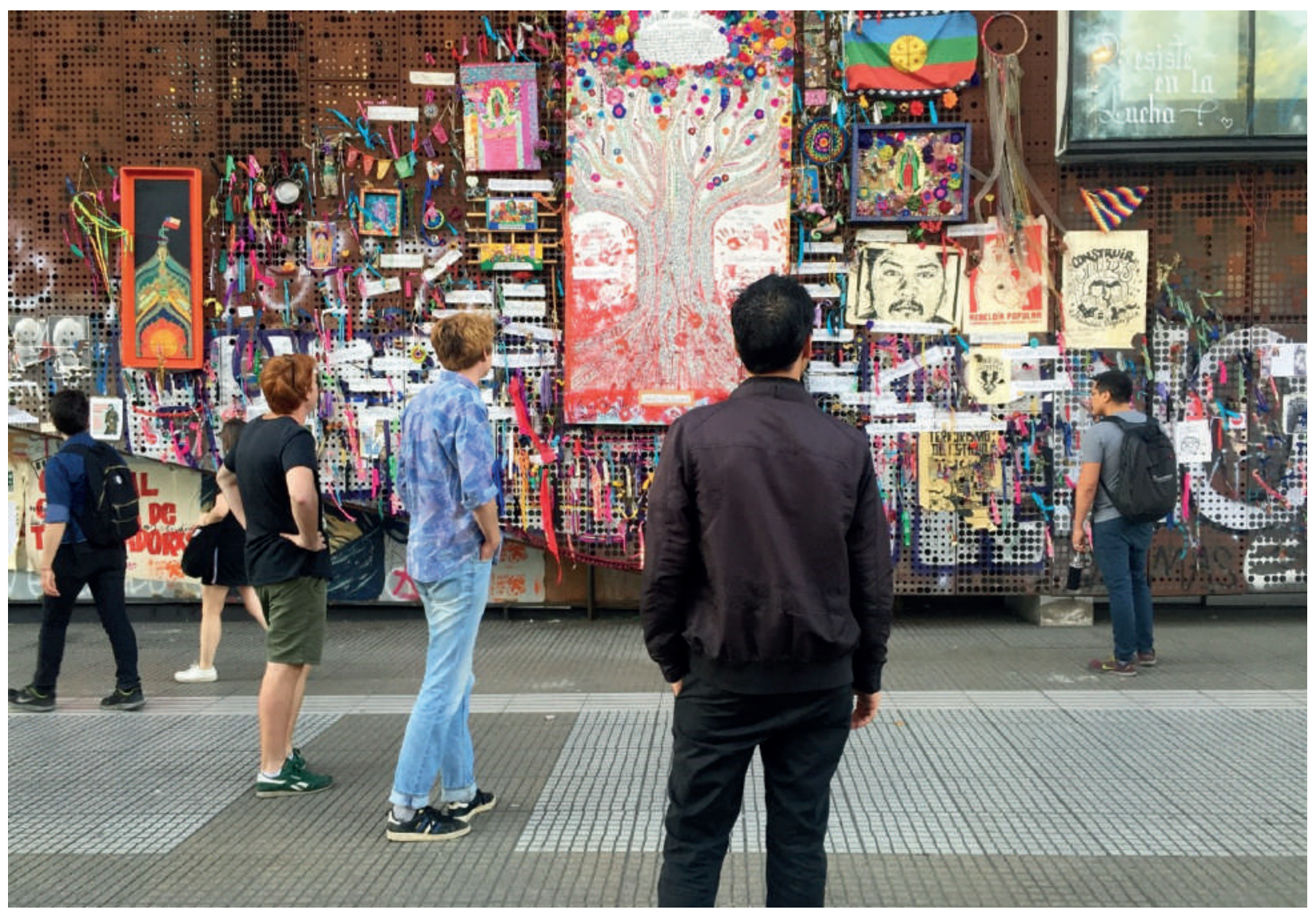




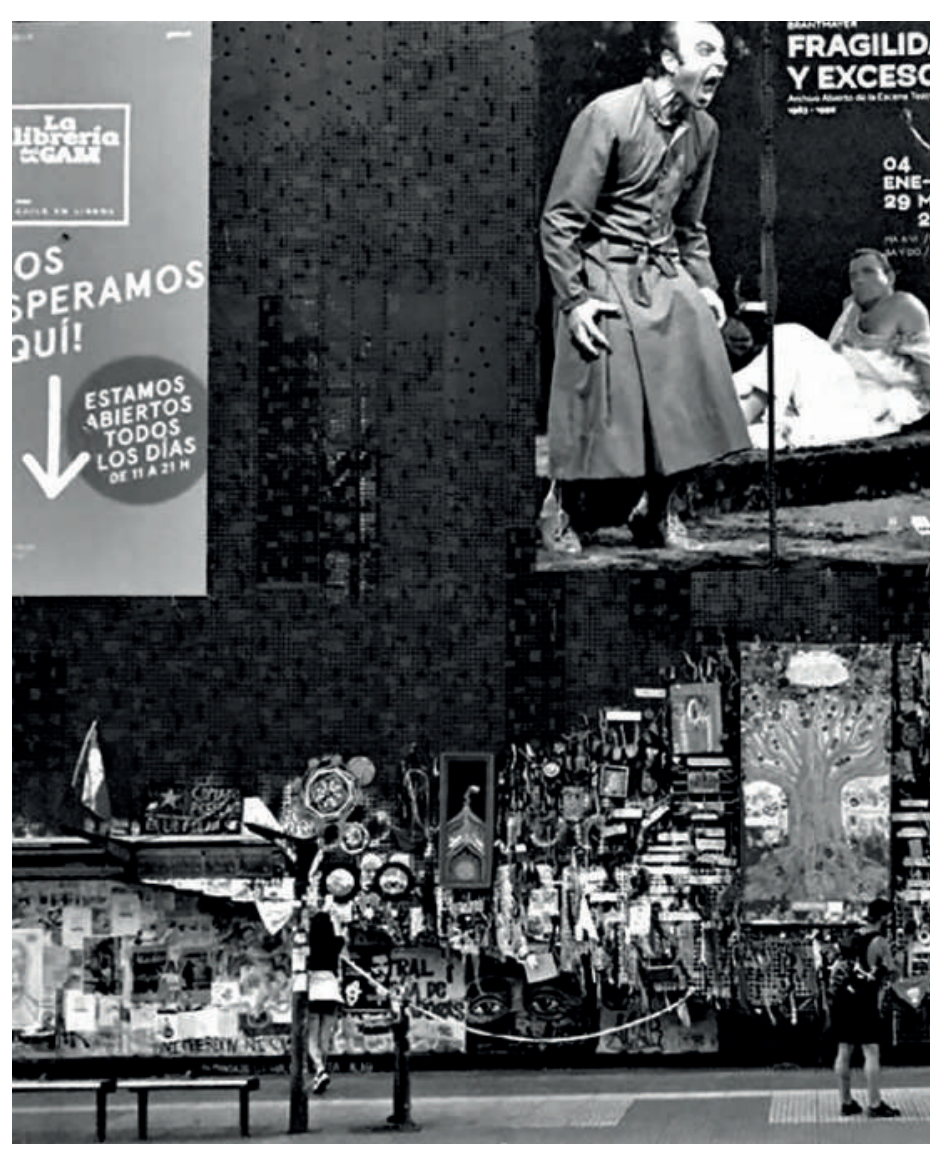

Figura 3

GAM blanco y negro, fotografía Fernando Dowling

https://www. instagram.com/p/B7pobPippLj/2020 albedrío, decisión, deseo, y disposición. El tatuaje constituye una reafirmación y confirmación valórica.

Los tatuajes urbanos responderán a la siguiente caracterización:

- Estrategia comunicacional: Inexistente. Solo se requiere comunicar, espontáneamente, demandas postergadas en el tiempo.

- Lugares: Apropiación del espacio público, utilizando predominantemente los zócalos de los edificios como lienzos comunicacionales urbanos.

- Expresión formal: Múltiples técnicas sobrepuestas: panfletos serigrafiados, tags, bubble ups, pósteres, grafitis, throw ups, fotocopias, murales, entre otras.

- Interacción con el usuario: Es una convocatoria abierta al que requiera comunicar. Una especie de twitter urbano. Es una apropiación del espacio público como hecho político.

- Significado: Gran interacción y sumatorias simultáneas de significados [Figura 4].
Figura 4 Laberinto, fotografía Fernando Dowling https://www.instagram.com/p/B65bTBepiux/2019

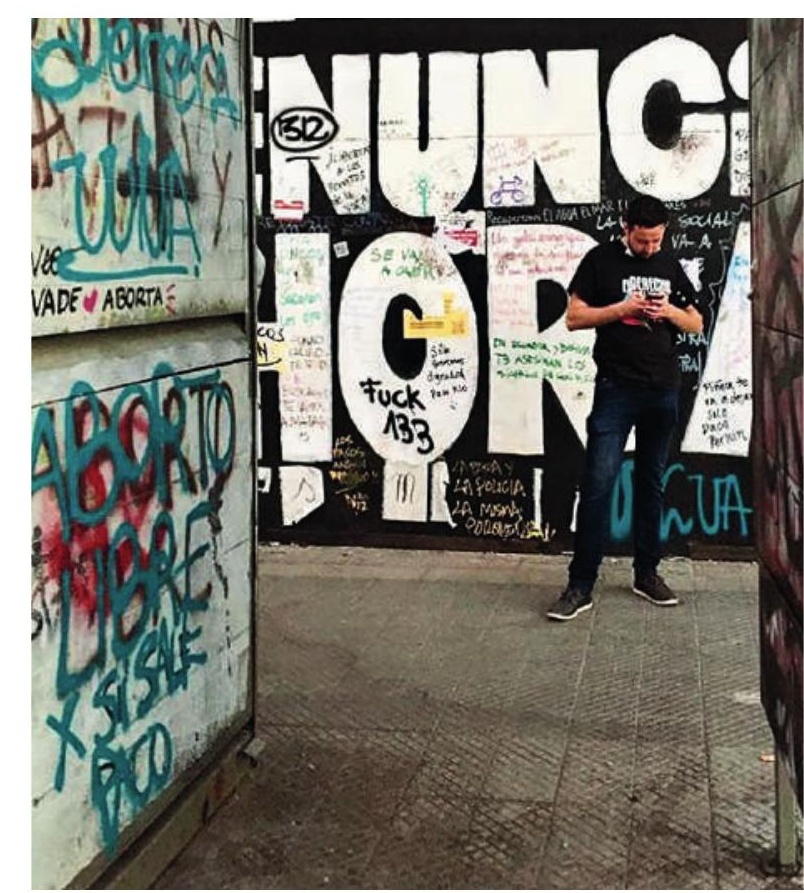




\section{CORPOREIDADES PERFORMÁTICAS Comunicación icónica cívica}

\section{Performance Voluntaria y efímera}

Se entiende por performance una actividad artística realizada por una o más personas, la cual tiene por objetivo instalar un tema mediante una improvisación teniendo contacto directo con el espectador.

Las temáticas de las performances realizadas durante este periodo utilizarán el cuerpo como vehículo que sustentará un relato comunicacional.

Los cuerpos se tatúan, convirtiéndose en herramientas que evidencian mensajes de denuncias de toda índole: Se transforman, momentáneamente, en lienzo artístico portador de una misiva. Son una corporeidad significante.

Las performances son una de las manifestaciones más recurrentes en las numerosas marchas que han sido vistas durante el Estallido Social chileno.

Distinguiremos dos categorías del género:

- La performance voluntaria y efímera como una acción planificada comunicacionalmente, la cual tendrá lugar durante un breve espacio de tiempo.

- La performance involuntaria y permanente, como aquellos personajes que provienen de las movilizaciones sin planificación ni ambición comunicacional, pero cuya intensidad escénica es tan relevante que pone de manifiesto valores con los cuales existe una poderosa identificación ciudadana, constituyéndose en memoria iconográfica popular.

La gran performance del movimiento social y feminista es, sin lugar a dudas, aquella creada por el Colectivo porteño LasTesis con el "Violador en tu Camino" [Figura 5]. Los cuerpos se convierten en instrumento y misiles de protesta con el objetivo de visibilizar la ausencia de justicia producto de la normalizada e histórica violencia de género.

Las variables en juego se determinan con la siguiente precisión:

- Estrategia comunicacional: La performance entendida como el cuerpo se transforma en lienzo comunicacional

- Lugares: Se realiza, generalmente, en espacios relacionados con instituciones del Estado que ejercen impunemente, violencia de género como son los retenes de Carabineros, Palacios de Justicia, espacios públicos de alta convocatoria.

- Expresión formal: Los cuerpos se mueven al son de un ritmo monótono y repetitivo, como si encarnase la respuesta sistematizada a la negación de producir un cambio en el sistema. Los ojos están vendados, la violencia requiere enceguecer a sus víctimas. La coreografía persiste en llevar aquel ritmo un tanto militarizado, pero logra liberarse, denunciando corporalmente a los opresores, produciendo de esta manera inflexiones en el ritmo. La letra es punzante, directa y a ratos irónica, no dejando dudas del foco central. La performance denuncia sin detenerse. La monotonía se transforma en iteración, en una repetición sinfín: Es la estrategia de cambio. 
- Interacción con el usuario: La performance es un espectáculo con espectadores

- Significado: La performance se convierte en himno y manifiesto de la revolución de género.

Por cierto que el fenómeno comunicacional de LasTesis, es bastante más complejo de analizar que solo mediante su expresión performática. En tal sentido, la repercusión que ha tenido a nivel mundial es la capacidad de identificarse con el mensaje. Prueba de aquello es que en cada país donde se ha reproducido, ha sufrido adaptaciones adecuándose al contexto local, universalizando aún más su mensaje.

El Violador en tu

Camino, Colectivo

Las Tesis. Foto-

grafía Fernando

Dowling, 2019

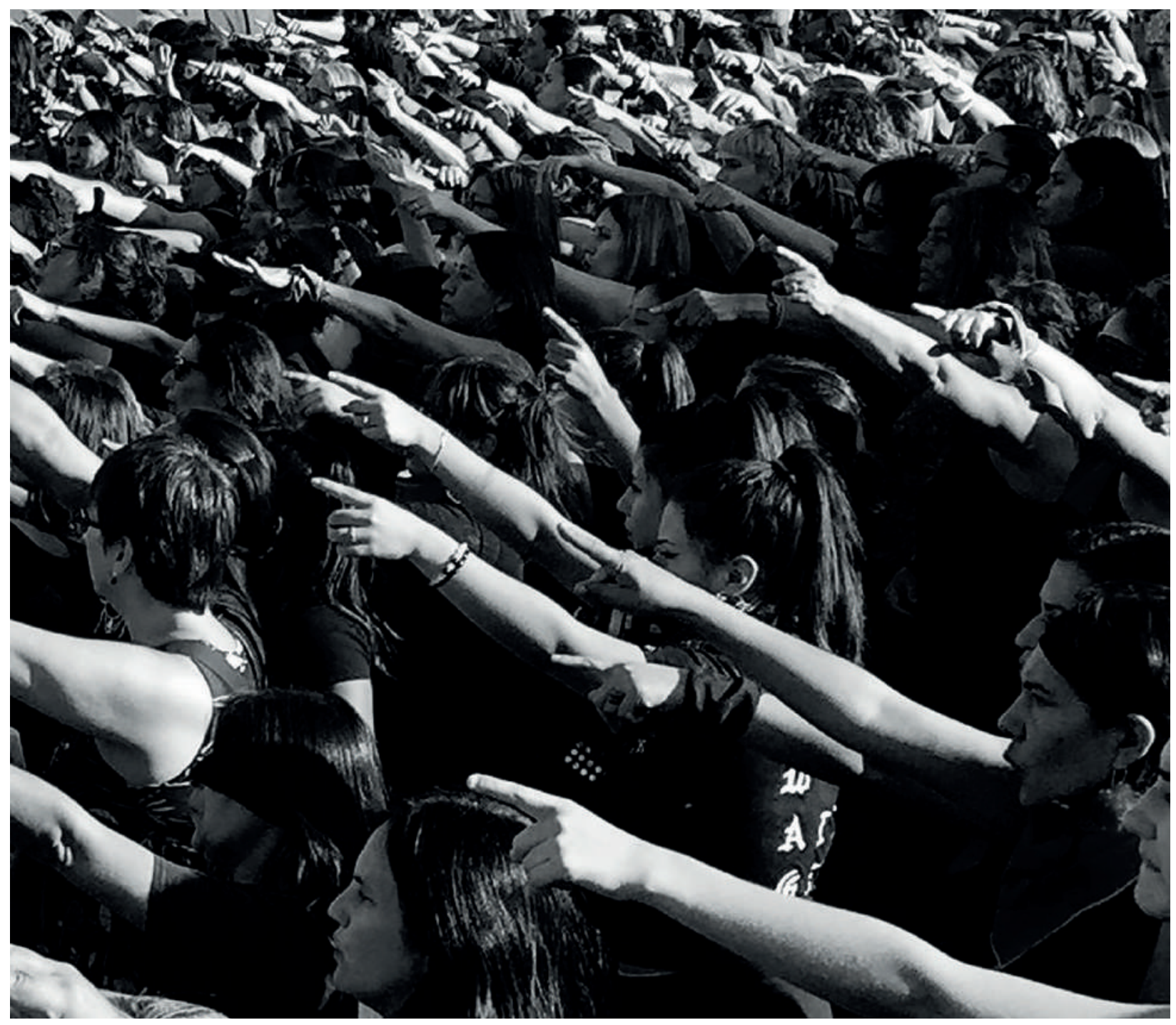




\section{De la Performance temporal involuntaria a la memoria iconográfica permanente}

Son las involuntarias e inconscientes performances de civiles, realizadas espontáneamente durante las marchas, las cuales se trasformaron en figuras performáticas iconográficas, originando reales mitos urbanos revolucionarios.

Según Oscar Salas, de Dogitia Editorial (Negro Matapacos, https://www.chvnoticias.cl/trending/negro-matapacos-pareman-baila-pikachu-manifestaciones-chile_20191/16/, 2019): "Son los símbolos de este siglo, que vienen del meme, de Internet. Hay una identidad generacional, un pueblo chileno, que está construyendo sus propios iconos a partir de su propia memoria" [Figura 6].

De esta forma encontramos que:
Figura 6

El Negro Matapaco, perro guardián de las protestas, icono y símbolo de la Primera Línea de lucha estudiantil, "franja de seguridad de las marchas" las que se enfrentan a las fuerzas de orden. Este, ha sido transformado en icono internacional del pueblo abusado, considerándolo como un guerrero ciudadano, el cual representa los valores del nuevo orden que se requiere instalar. Mural de Claudio Caiozzama en el edi ficio Centro Cultural Gabriela Mistral. Fotografía Fernando Dowling

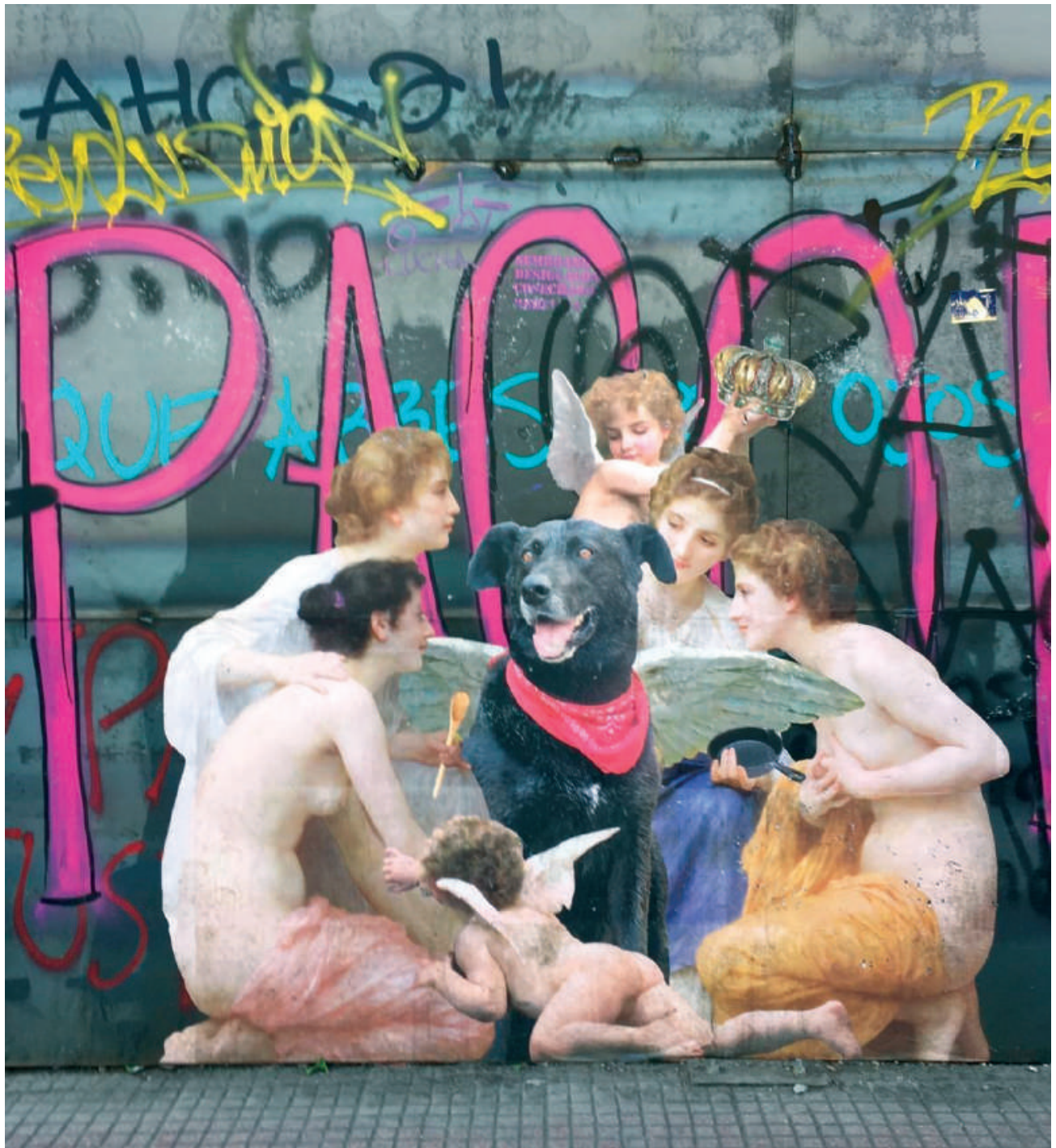


- Estrategia comunicacional: El meme es su campo comunicacional

- Lugares: Surgen de las marchas, como personajes reales, para luego convertirse en Iconos puestos a disposición de las redes sociales.

- Expresión formal: Estas performances "involuntarias" son convertidas en comics de un innovador "Nuevo Ejercito Libertador". Su caracterización nos trae a soldados ciudadanos, luchadores, y guerreros dispuestos en el campo de batalla. Corresponden a la tipología del superhéroe [Figura 7].

- Interacción con el usuario: Se transforman en recursos digitales.

- Significado: Representan un campo valórico renovado, los cuales enaltecen los principios de dignidad, valentía, rebeldía, anonimato, picardía y justicia como la instauración de un nuevo constructo popular.

Figura 7 Los Avengers chilenos. Dibujo de CABZ y Mr. Marsupial, https://www.chvnoticias.cl/trending/ negro-matapacos-pa-
reman-baila-pikachu-manifestaciones-chile_20191116/, 2019

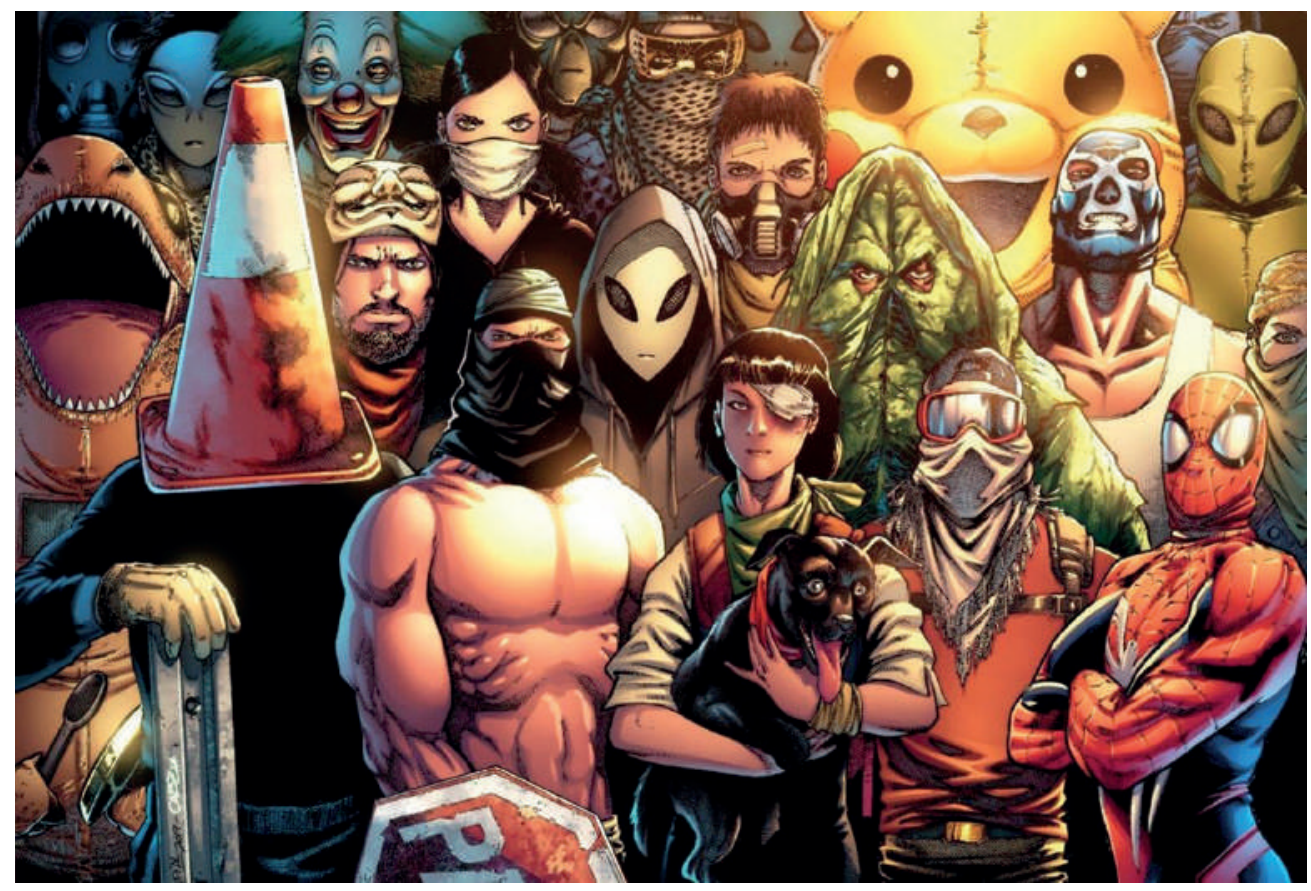




\section{LAS INSTALACIONES Comunicación y resignificación urbana}

Según el glosario Nacional del Museo de Bellas Artes de Chile:

\begin{abstract}
(...) una instalación artística es un género de arte contemporáneo que surge en la década de los años 1960 en la idea de que la obra prevalece sobre sus aspectos formales. Es parte de la forma experimental artística, se exhibe por un tiempo predeterminado y se puede presentar en cualquier espacio. Una instalación se realiza en y para un contexto y espacio determinado. Por definición, tiene una duración determinada y, por ende, entra dentro de lo que se conoce como arte efímero. En la mayoría de los casos permite una interacción activa con el espectador. (Museo Nacional de Bellas Artes, https://www. artistasvisualeschilenos.cl/658/w3-article-54879.html, 2019)
\end{abstract}

La mayoría de las instalaciones han tenido un componente común: constituirse en medios comunicacionales de denuncia que logran complementar los mensajes insertos en las movilizaciones. Son actos comunicacionales de tomo y lomo, manifiestos políticos donde la claridad del mensaje no puede dar origen ni lugar a equívocos.

Las plataformas comunicacionales de dichas instalaciones, al igual que los tatuajes urbanos, han tenido como soportes y lienzos de difusión la ciudad y sus obras de arquitectura emblemáticas, hitos urbanos reconocibles para toda la ciudadanía, instituciones relacionadas con comunicaciones, espacios públicos y esculturas de los grandes próceres de la historia nacional.

Existe una prevalencia de instalaciones nocturnas por sobre las diurnas, probablemente por los niveles de complejidad que conlleva una producción a la luz del día. Este criterio ayudará a editarlas y a relacionarlas conforme a la interacción con el usuario, discerniendo las diurnas, con mayor interacción de público, de las nocturnas, que serán masivamente visualizadas a través de las redes sociales.

\section{Diurnas en interacción con el público}

Las instalaciones diurnas poseen la libertad de interactuar con el usuario de manera más libre y directa. Su contraparte es que la producción tiene que ser muy planificada, de manera que su despliegue escénico pueda ser rápido y eficiente. Nos detendremos en un caso dinámico, flexible, de bajo costo y de óptima interacción con el usuario de las marchas.

\section{\#hablemosdeviolencia, colectivo @elpuevlo}

- Estrategia comunicacional: este colectivo pone sobre la mesa relacionar la violencia del sistema con aquella vivida cotidianamente por la ciudadanía, develando y poniendo en evidencia, una relación "violenta" asimétrica. La estrategia comunicacional es de impacto y a bajo costo [Figura 8].

- Lugares: los lugares elegidos para las instalaciones son los paraderos de transporte público, los quioscos y cajas de luz pu- 
ARQUITECTURA EFÍMERA

blicitarias que han resultado destruidos como consecuencias de las movilizaciones. Son espacios genéricos, urbanamente hablando, donde transita un flujo importante de personas.

- $\quad$ La Instalación: Carteles realizados en papel, fijados con abrazaderas parasitariamente al paradero, quiosco o caja de luz. Mensajes con un lenguaje preciso y acotado

- Interacción con el usuario: Considerando que las instalaciones se disponen en lugares transitados y al paso, la interacción con el público es rápida y eficiente. Mensajes logran una empatía instantánea.

- $\quad$ Significado: El significado es cerrado, preciso y acotado. El usuario no requiere significarlo al menos que no esté de acuerdo con el mensaje, para lo cual puede intervenirlo.

Figura 8

\#hablemosdeviolencia, colectivo, a elpuevlo https:// www. instagram.com/ elpuevlo/,2019
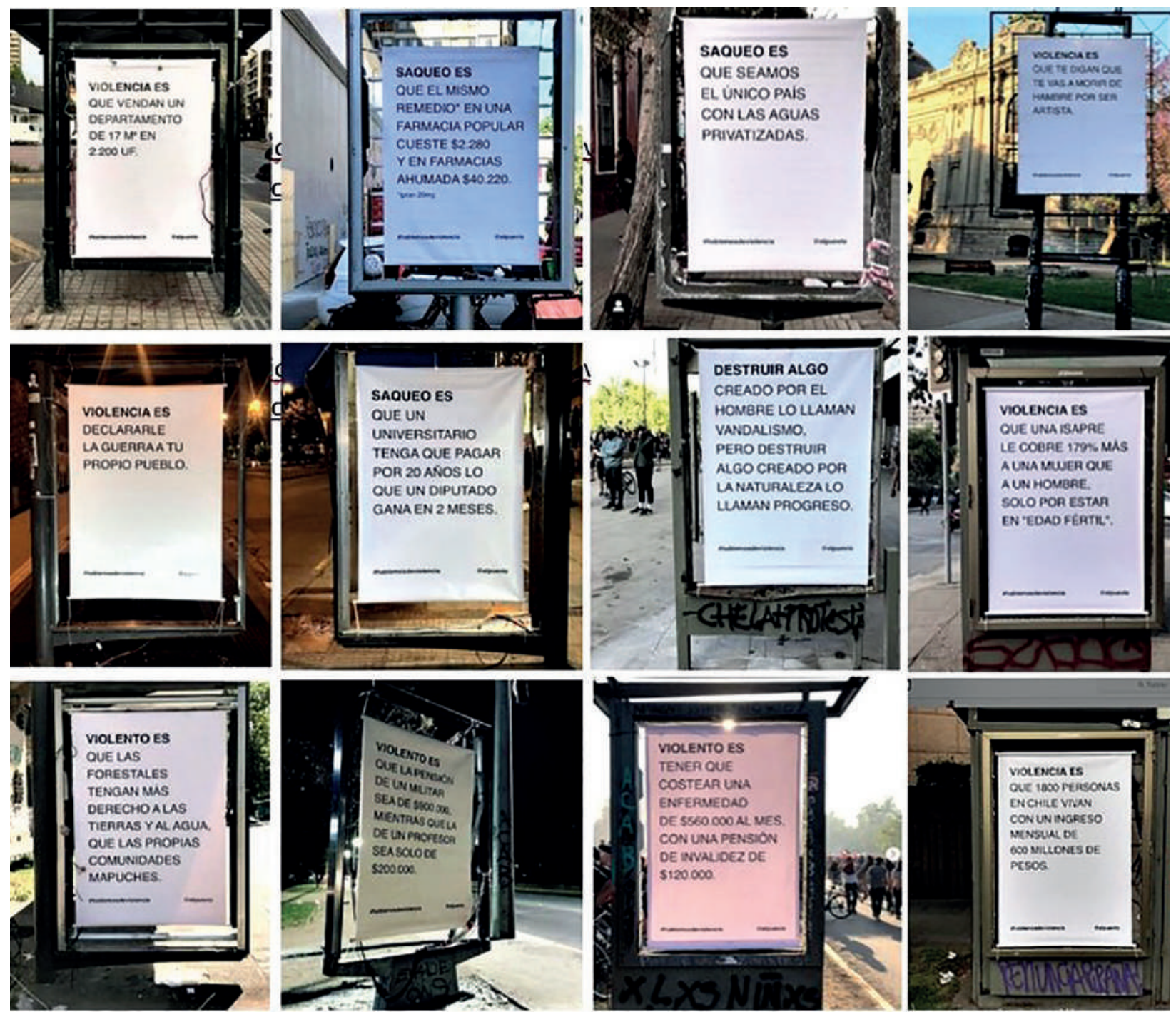


\section{Nocturnas, sin relación (directa) con el público}

Las proyecciones nocturnas conforman las envolventes que originan una relectura del paisaje cotidiano urbano, una transformación de aquellas arquitecturas convertidas en soportes dispuestos para el espectáculo.

Espectáculo direccionado hacia el mundo de las palabras, mundo de la exactitud, de la objetividad, de lo inapelable, muy distante al mundo de las imágenes, el cual se caracteriza por sus niveles de sugerencia e interpretación personal. Los significados son cerrados, reflexivos, y el diálogo entre palabra y obra de arquitectura logran producir la expectación necesaria para convertir a la instalación en un espectáculo urbano.

La arquitectura entonces, desde su legitimidad cotidiana de ser reconocida por sus habitantes como una obra para el ciudadano, se reviste de un nuevo significado urbano, convirtiéndose en un mensaje temporal.

Las obras y espacios públicos arquitectónicos más emblemáticos del país tuvieron a bien convertirse en mensajeros momentáneos. Las más destacables se han enmarcado en un ámbito de poca interacción con los manifestantes; es decir que su modo de difusión ha sido mediante videos y fotografías subidas a las redes sociales, lo cual permite una mayor permanencia y exposición en el tiempo.

Genéricamente, su comportamiento, se describe de la siguiente manera:

- $\quad$ Estrategia comunicacional: La estrategia es la denuncia. Pronunciarse en voz alta y a gran escala de manera de tener el mayor alcance posible. Las redes sociales son el segundo medio de difusión [Figura 9].

- Lugar: Edificios icónicos urbanos

- Instalación:Técnica del mapping, donde la proyección de una frase o una imagen, son el foco de la denuncia establecida por la estrategia comunicacional.

- Interacción con el usuario: Interacción a la distancia, sin posibilidad de resignificar la obra. Interacción intelectual en redes sociales.

- $\quad$ Significado: El poder de la palabra es una realidad en sí, la cual inscribe su significado a un contexto específico. La interpretación es casi nula.

\section{Nocturna-diurna}

Existe una sola instalación a la fecha, que ha sido objeto de más de una lectura, lo que la sitúa en un escenario diferente: Se trata de la instalación PAZ [Figura 10], la que fue inaugurada al amanecer siguiente que los políticos lograron El Acuerdo por la Paz Social y la Nueva Constitución.

La instalación tuvo como objeto blanquear la superficie de la Plaza de la Dignidad, mediante telas, lugar que marca el epicentro 


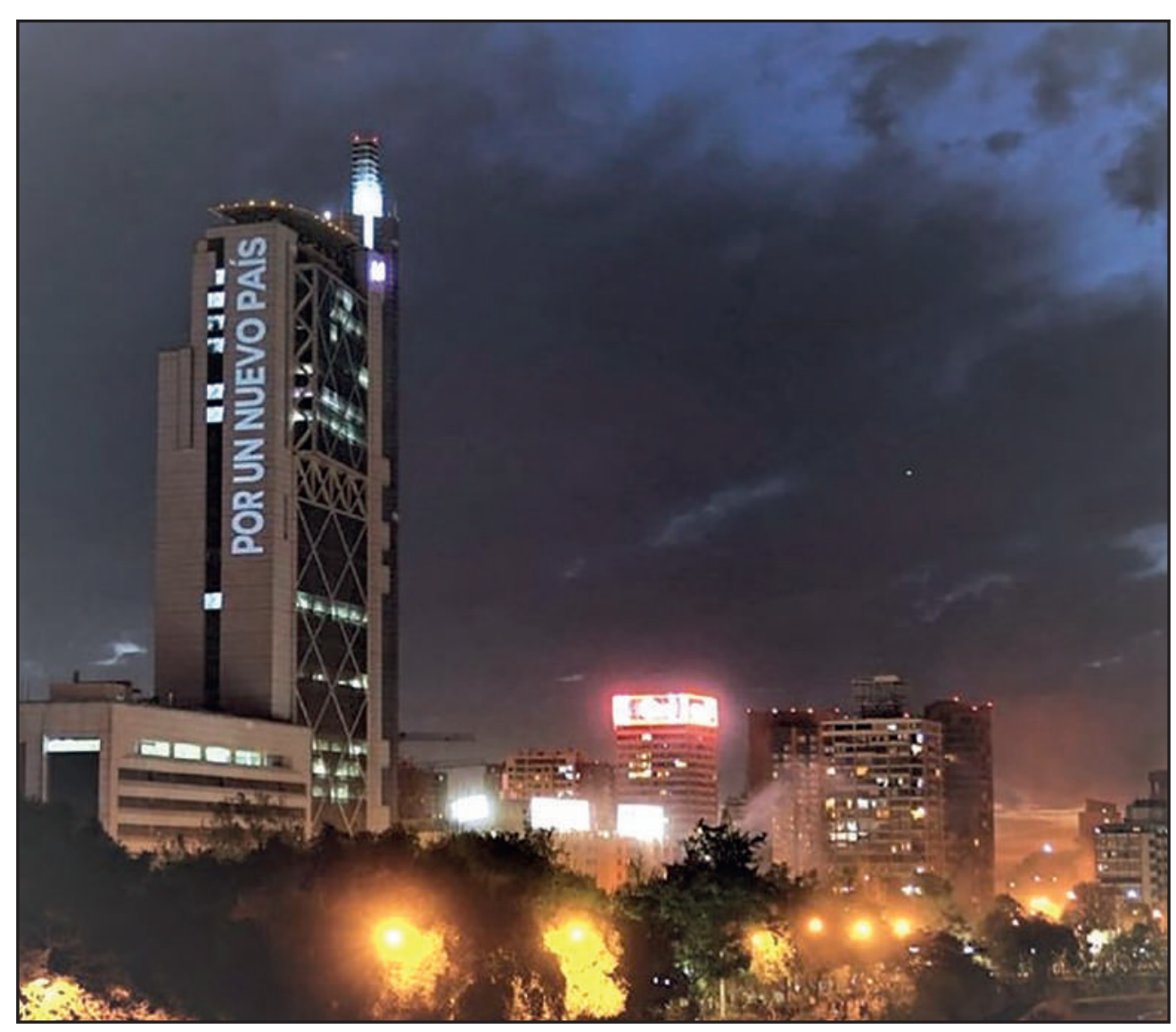

Figura 9

Por un nuevo país, Edificio Telefónica Chile, Santiago de Chile, Delight Lab Estudio,

https://www. instagram.com/p/B4OeQleJT1r/?igshid=a5go7 de $5 \times 4$ wa

de las demandas ciudadanas, dejando sobre el Monumento al General Baquedano la palabra "PAZ". El horario en que se instala es al amanecer, por lo que no existió una interacción con la ciudadanía. Su fugaz existencia es conocida mediante un registro fotográfico y un video. La Academia de Líderes Católicos de Chile podrían ser sus autores.

Su caracterización comunicacional se describe de la siguiente forma:

- Estrategia comunicacional: Representar la paz mediante el color blanco. La estrategia comunicacional será fundamentalmente mediante redes sociales.

- Lugar: Plaza de la Dignidad

- Instalación: Se entela el suelo de los jardines de la Plaza de la Dignidad y se dispone un letrero sobre el Monumento al General Baquedano con la palabra PAZ.

- Interacción con el usuario: No hubo

- Significado: El blanco da origen a plantearse dos escenarios: 
El primero, el blanco de la paz, el blanco de la re-inauguración, la posibilidad de comenzar todo desde el inicio, momento que puede dar origen a una refundación de un nuevo país. Bajo este significado, la palabra PAZ no hace ruido, pues el significado blanco es más fuerte y predominante.

El segundo posible significado podría asociarse con la necesidad de blanquear de la superficie todo lo que allí ha sucedido. La palabra PAZ, en ese contexto, viene a subrayar la necesidad imperiosa de restablecer la normalidad a como dé lugar.

Probablemente, si se hubiera incluido a la ciudadanía en esta instalación, pudiese haber existido un interesante aporte.

El interés de esta puesta en escena radica en la posibilidad de significarla de manera casi opuesta, conforme a la cultura y la perspectiva del observador.

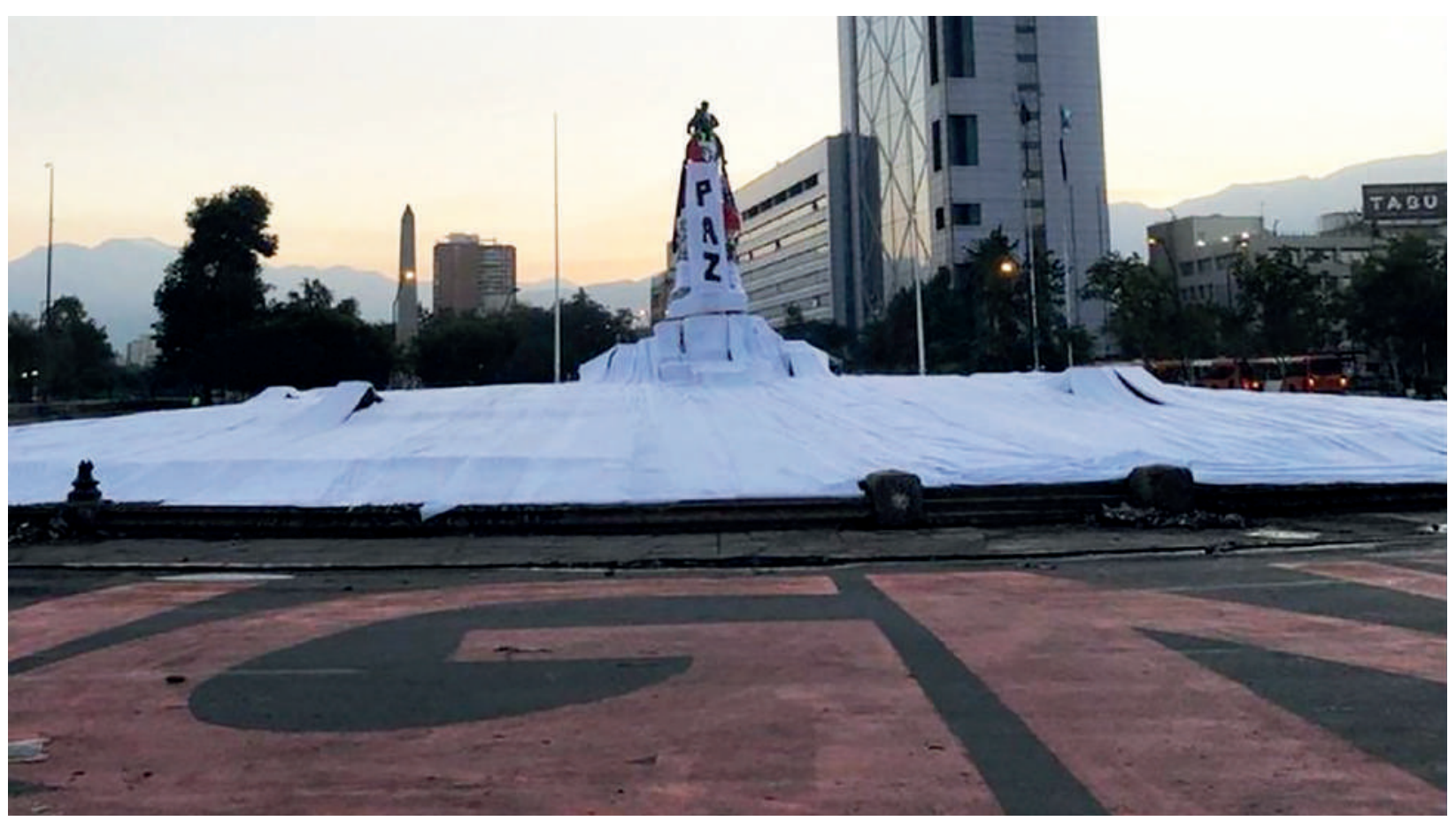




\section{REFLEXIONES}

Entenderemos a la ciudad como entidad corpórea, por cuanto decodificará la información recibida, atribuyéndole un nuevo significado. Corporeidad que distinguirá tres modalidades: una comunicación confidencial, una icónica y una resignificante.

\section{Ciudad y Comunicación confidencial}

Los Tatuajes urbanos constituyen un sistema simbólico, donde la ciudadanía busca ser acogida y escuchada por la ciudad, requiriendo imprimir sus mensajes sobre ella. La urbe, en esta apropiación, se transforma en cómplice y confidente de su ciudadanía. En esta activa relación, los tatuajes urbanos, constituyen el cuerpo más espontaneo, dinámico y expuesto relativo a las instalaciones temporales, los cuales trastocaran momentáneamente los significados de la metrópolis.

\section{Comunicación icónica cívica}

La nueva raza de héroes y heroínas nacionales, personajes épicos que deambulan en las marchas, son considerados los nuevos iconos populares, guardianes de la dignidad del pueblo. Aquellas figuras de la vida cotidiana, como el Negro Matapacos, son dispuestos en el altar de las heroínas y héroes nacionales. Son los nuevos representantes de los innovados valores cívicos y es en la ciudad, junto al pueblo, donde su actuar resulta relevante.

\section{Comunicación y resignificación urbana}

Las instalaciones conforman el sistema comunicacional más sofisticado y el menos improvisado de todos. El cuerpo arquitectónico se viste para la ocasión, cambiando su cotidianidad por excepcionalidad, resignificándose en una nueva condición de mensajero urbano. 


\section{CONCLUSIONES}

Las representaciones del cuerpo y los saberes acerca del mismo son tributarios de un estado social, de una visión del mundo y, dentro de esta última, de una definición de la persona. El cuerpo es una construcción simbólica, no una realidad en sí misma. En este sentido, las representaciones sociales le asignan al cuerpo una posición determinada dentro del simbolismo general de la sociedad. Sirven para nombrar las diferentes partes que lo componen y las funciones que cumplen, hacen explícitas sus relaciones, penetran el interior invisible del cuerpo para depositar allí imágenes, le otorgan una ubicación en el cosmos y en la ecología de la comunidad humana. Este saber aplicado al cuerpo es, en primer término, cultural. (Micieli, 2007, p. 65)

El estallido social chileno ha sido un movimiento acéfalo, el cual surge de manera espontánea como consecuencia de años de abusos.

En ese contexto, las manifestaciones efímeras reportadas son expresiones que no provienen de estrategias comunicacionales institucionales, sino de iniciativas ciudadanas espontáneas, atribuibles a personas. Estas logran captar el espíritu del movimiento, realizando un constructo comunicacional ideado sobre la marcha, in situ, donde la ciudad, es el espacio de todas, todos y todes. Como lo menciona Cristina Micieli, (Micieli 2007, p. 49) "La visión del cuerpo pertenece a un momento histórico específico y cambia a la par de éste". La construcción de esta corporeidad comunicacional se expresa a modo de un espectáculo donde la ciudad, como cuerpo urbano resignificado por el ciudadano, se connurba con él, transformándolo por un tiempo aun indefinido. La ciudad se convierte en un cuerpo consciente, es decir, transmuta a una condición de corporalidad. Corporalidad urbana al servicio de estrategias comunicacionales espontáneas, diversas y, por sobre todo, ciudadanas.

El cuerpo es el medio que permite la conciencia del mundo, ya que a este último vivimos reduciéndolo a las posibilidades de nuestro cuerpo. Cualquier transformación del cuerpo redefine lo que percibimos y lo que podemos conocer. La visión del cuerpo participa en la génesis del mundo, de ahí la relevancia de su investigación teórica. (Merleau Ponty, 1993) 
MICIELI, C. El cuerpo como construcción cultural. Santiago: Aisthesis. 2007.

MONTENEGRO, M., ORNSTEIN, C., TAPIA, P. Cuerpo y corporalidad desde el vivenciar femenino. Santiago de Chile, Acta Bioethica, 2006

Museo Nacional de Bellas Artes de Chile. «Instalación». Glosario del Museo Nacional de Bellas Artes de Chile. Consultado el 2 de julio de 2019

TÉVOZ, M. The painted body: the illusions of reality. New York: Rizzoli. 1984.

WALZER, A. Tatuaje y significado: en torno al tatuaje contemporáneo. Madrid, Revista de humanidades. 2015.

https://www.instagram.com/elpuevlo/,2019

https://www.instagram.com/p/B44kAaAnrRt/, 2019

https://www.nomadbubbles.com/tatuajes-tribales/

https://elpinguino.com/noticia/2019/10/25/en-magallanes-no-estamos-enguerra-y-por-eso-apostamos-por-la-luz

www.delightlab.com

https://www.publimetro.cl/cl/social/2019/10/04/nalcamam-superheroe-chileno-corporeo-puerto-montt-disfrazado-hojas-nalca-viral.html

https://www.chvnoticias.cl/trending/negro-matapacos-pareman-baila-pikachu-manifestaciones-chile_20191116/

https://www.adnradio.cl/noticias/sociedad/llamativas-frases-se-han-tomado-el-edificio-de-telefonica-de-providencia-durante-las-noches/20191023/ nota/3970276.aspx 